\title{
ENUNCIADOS NO COMPROMETIDOS Y PUNTO DE VISTA JURÍDICO: UNA PERSPECTIVA RENOVADA
}

\author{
Diego Dei Vecchi \\ Instituto Tecnológico Autónomo de México (ITAM) \\ Departamento Académico de Derecho \\ deivecchidm@gmail.com
}

\begin{abstract}
RESUMEN: El autor pone en duda la posibilidad de una ciencia jurídica acorde a las exigencias del positivismo jurídico normativista, según el cual describir el derecho es dar cuenta neutralmente de lo que jurídicamente se debe hacer. Replantea la tesis de Joseph Raz de que, para proferir enunciados descriptivos tales, debe adoptarse hipotéticamente el punto de vista jurídico, en sí mismo moralmente comprometido; según esa tesis, una ciencia jurídica acorde a las exigencias ha de pronunciarse profiriendo enunciados de un tipo que Raz denomina "no comprometidos". El texto aborda varias posturas críticas contra esta visión y muestra que si bien es posible rechazar la tesis de Raz tal como la postula, se corre el peligro de descartar como no problemático más de lo plausiblemente descartable. Así, recurriendo a dos viejas discusiones de la filosofía del derecho reformula y da plausibilidad a la tesis de la necesidad de asumir el punto de vista jurídico.
\end{abstract}

PALABRAS CLAVE: ciencia jurídica, positivismo jurídico, enunciados jurídicos, proposiciones normativas, neutralidad

SUMMARY: The author calls into question the possibility of a legal science in accordance with the requirements of normative legal positivism, which holds that to describe the law is to give an account of legal rights and duties. To evaluate the possibility of this program the author reformulates Joseph Raz's thesis which states that legal scientists must adopt the legal point of view; to this end they must proffer statements of a peculiar type, which Raz has called detached legal statements. This paper attempts to show that even though the thesis can be rejected as Raz postulates it, this would risk discarding as "non-problematic" more than what is reasonable to discard. Thus, resorting to two familiar discussions in the philosophy of law, the "legal point of view thesis" is reformulated and shown as plausible.

KEY WORDS: legal science, legal positivism, legal statements, norm proposition, neutrality

\section{Introducción}

Uno de los aportes más destacados de Joseph Raz a la teoría del derecho ha sido señalar la presencia en el discurso jurídico de los por él denominados "enunciados jurídicos no comprometidos" (detached legal statements): enunciados informativos acerca de lo jurídicamente debido, proferidos sin asumir compromiso moral alguno, es decir, neutralmente. ${ }^{1}$ Según Raz, en la medida en que la ciencia jurídica

${ }^{1}$ En la traducción española de Raz 1979a se los denomina enunciados imparciales. 
tenga la pretensión de informar sobre los deberes jurídicos de los ciudadanos, habrá de expresarse necesariamente por medio de ese tipo peculiar de enunciados.

Para el autor, usar sincera y típicamente términos deónticos entraña la creencia en la presencia de razones para la acción, al tiempo que esto último implica, por su parte, un compromiso de carácter esencialmente moral (Raz 1979c, p. 63). En consecuencia, el uso de estos términos se torna en principio incompatible con una ciencia del derecho como la que el positivismo jurídico normativista ambiciona: no sería posible identificar e informar neutralmente sobre el contenido del derecho, sobre los deberes que impone, ya que pronunciarse sobre ello significaría expresar un compromiso moral en desmedro de la neutralidad valorativa a que la ciencia exhorta (Raz 1979d, p. 306, Raz 1999 [1975], p. 127). ${ }^{2}$

No obstante, para Raz gran parte del discurso jurídico consiste de hecho, casi misteriosamente, en proferir enunciados auténticamente informativos y neutrales sobre lo jurídicamente debido. Así se desenvuelve, según él, el discurso que sobre el derecho despliegan juristas, profesores de derecho e incluso ciudadanos comunes. Más, así se configura el discurso paradigmático de los auténticos científicos del derecho. ${ }^{3}$ Pero ¿cómo es esto posible?

Comprender este fenómeno, piensa Raz, requiere la elucidación del dispositivo discursivo que hace posible este uso "científico" del lenguaje normativo, uso pulcramente informativo. Y para lograr una elucidación tal bastaría con rechazar la bipartición que Hart trazó y tornó popular con respecto al discurso jurídico, a saber: la que distingue entre enunciados jurídicos internos y enunciados jurídicos externos como categorías exhaustivas. Dicho rechazo iluminaría este "tercer tipo" de discurso, constituido precisamente por los enunciados no comprometidos, oscurecido tras la encorsetada dualidad hartiana aunque ya presente en las intuiciones kelsenianas. Son precisamente estos enunciados los que hacen posible pronunciarse sobre lo debido sin comprometerse moralmente. Sólo por medio de los enunciados no comprometidos es factible informar sobre lo que debe

\footnotetext{
${ }^{2}$ Véase una presentación sumamente clara del (presunto) problema que aqueja a Raz en Duarte d'Almeida 2011, § 1.

${ }^{3}$ Asumiré en lo que sigue, aunque sin suscribirla, la tesis de la metateoría prescriptiva, i.e., la directiva metodológica según la cual lo que la ciencia del derecho ha de hacer es informar sobre lo que jurídicamente debe hacerse en determinado ordenamiento, sin que el deber se reduzca a ciertos hechos, o se identifique con ellos, aun cuando (necesariamente) superviene de ellos (tesis de las fuentes sociales). Véanse, en este sentido, Kelsen 2009 [1960], pp. 88-93, y Kelsen 1985 [1979], p. 236.
} 
hacerse, a partir de la asunción hipotética del punto de vista moralmente comprometido (i.e., el punto de vista de quienes adhieren a la validez del sistema normativo en términos de fuerza vinculante $\mathrm{u}$ obligatoriedad, quienes lo ven como si proporcionara razones genuinas para la acción).

Mucho se ha dicho acerca de los enunciados no comprometidos desde que Raz los introdujese en la agenda de discusión iusfilosófica. El propio Hart se empeñó en responder a la crítica mencionada, ${ }^{4}$ y autores como MacCormick y Bankowski (1986), MacCormick (1994 [1978]), Shiner (1992), o Finnis (2011), por citar sólo a algunos, pusieron especial atención en ellos. Eugenio Bulygin, y más recientemente Luis Duarte d'Almeida, con argumentos variados han socavado las bases de la categoría raziana. El último ha sostenido incluso que de por sí el problema que Raz se planteaba (i.e., el de proferir enunciados descriptivos, neutrales, acerca de lo que jurídicamente se debe hacer) es lisa y llanamente un falso problema para el teórico. Para ambos autores, un observador puede, profiriendo enunciados externos hartianos, hacer todo lo que una ciencia jurídica positivista requiere para informar sobre lo que según el derecho se debe hacer. Otro crítico reciente ha sido Kevin Toh, para quien los enunciados no comprometidos no constituyen tampoco una categoría independiente a las dos hartianas. Para este último, sin embargo, los enunciados no comprometidos serían un tipo especial de enunciado interno (Toh 2007).

Por su parte, Nicola Muffato ha sostenido convincentemente que las tres líneas de crítica mencionadas en última instancia presuponen el rechazo del cóctel semántico, metaético y metafísico en que Joseph Raz cimienta su visión sobre el derecho y la teoría del derecho. Sin embargo, agrega, ninguna de las tres líneas objetoras justifica ese rechazo. Entre las tesis en cuestión, habrían de mencionarse aquí, principalmente, la concepción externista/objetivista de las razones para la acción, la suscripción de la tesis de la unidad del razonamiento práctico y la idea según la cual los términos deónticos mantienen su significado y expresan el mismo compromiso normativo típico en cualquier contexto normativo. De tal modo, al partir de presupuestos metaéticos distintos, las críticas antedichas se tornan en cierta forma inocuas, al menos en tanto no logren superar ese escollo y desbaratar las mencionadas asunciones. ${ }^{5}$

${ }^{4}$ Véanse Hart 1982, y Hart 2012.

${ }^{5}$ Sobre esta iniciativa, al menos en relación con algunas de esas tesis, véase Bayón Mohino 1991. 
En lo que sigue pretendo manifestar algunas dudas adicionales con respecto a los argumentos en que se basan las críticas aludidas, aunque partiendo de la asunción de que, por hipótesis, ellas superan con éxito el mencionado escollo. La pregunta es: aun asumiendo que el problema debe efectivamente rechazarse en su versión raziana, y aun descartando consecuentemente a los enunciados no comprometidos que de esa versión derivan, ¿no queda acaso todavía algo de plausible en la intuición según la cual para describir qué es lo que según el derecho se debe hacer ha de asumirse un punto de vista específico en términos normativos?

Sugeriré en este sentido que los argumentos desarrollados por los críticos a Raz son todavía insuficientes para estos fines y que, de tal modo, esa tesis - i.e., la "tesis del punto de vista jurídico"guarda todavía plausibilidad, aunque reformulada. Para mostrarlo se traerán a colación viejos problemas irresueltos de la teoría del derecho a partir de los cuales se sugerirá que, si se pudiese describir el contenido del derecho, esto es, si se pudiesen proferir enunciados de deber jurídico en sentido descriptivo - para evocar a Kelsen-, esto sólo se podría hacer sobre la base de la adopción y el uso de ciertas normas; ergo, desde el punto de vista interno. Si la pretensión de estar profiriendo aserciones en tales circunstancias no es más que una ilusión, la empresa descriptivista de aquello que jurídicamente debe hacerse habrá de reconocerse como una sucesión de actos de habla infelices: una emisión de enunciados constitutivos acaso de una "pseudo ciencia, incapaz de expresar conocimiento" (Caracciolo 2013, p. 42). Pero la discusión sobre la plausibilidad o no de esta pretensión habrá de dejarse para otra oportunidad. ${ }^{6}$

Como primer paso, en la sección 2 se avanzará sobre el problema de la necesidad de asumir el punto de vista jurídico y sobre la noción de enunciado no comprometido tal como Raz los postuló originariamente. Esto sólo como punto de partida, dado que en los aspectos más relevantes las objeciones de los críticos mencionados se presupondrán como correctas en lo que a esa versión originaria del problema concierne. A continuación, en la sección 3 se intentará reformular ese problema sobre la base de algunos de los argumentos

${ }^{6}$ El presente texto constituye el núcleo de una de las premisas de un trabajo más abarcativo. En ese trabajo, y por medio de esta premisa, se llega a una conclusión escéptica (aunque condicional) acerca de la posibilidad de un discurso genuinamente informativo-descriptivo sobre lo que jurídicamente debe o no debe hacerse. Este punto no puede ser abordado en este trabajo por cuestiones de extensión pero, en todo caso, creo que la premisa que aquí se postula amerita una discusión independiente. 
que conducen a rechazarlo como un genuino inconveniente para el positivismo jurídico. En las secciones 4 y 5, partiendo de esa reformulación, se aludirá a algunas discusiones abiertas en la filosofía del derecho con el fin de dotar de cierta plausibilidad a la necesidad de adoptar el punto de vista jurídico para informar sobre lo que de conformidad al derecho se debe hacer. En la sección 4 se tratará el problema del significado de los enunciados de deber jurídico y su relación con las proposiciones normativas. En la sección 5 se abordará el problema de la existencia de normas jurídicas y de la necesidad de contar con criterios de pertenencia de normas a sistemas jurídicos.

\section{Los enunciados jurídicos no comprometidos}

Como se adelantó, el positivismo jurídico normativista pretende, al menos en principio, tener capacidad informativo-descriptiva acerca de lo jurídicamente debido, reconduciendo esa respuesta a una serie de hechos sociales (tesis de las fuentes sociales). Esto así, en cualquier caso, sin reducir los enunciados deónticos a hechos y sin comprometerse moralmente con la corrección o incorrección del deber sobre el que presuntamente se informa (tesis del no reduccionismo y tesis de la neutralidad, respectivamente) (Raz 1979c, p. 54). ${ }^{7}$

Ahora bien, para Raz, al igual que para Kelsen, los términos deónticos como "derecho", "deber" u "obligación" tienen idéntico significado si son usados en contextos morales o jurídicos. Llamemos a esto "tesis semántica raziana". De esta tesis se seguiría que todo enunciado deóntico (i.e., un enunciado que usa términos deónticos como predicados de acciones) conlleva en cualquiera de esos contextos, al menos en principio, el mismo tipo de compromiso normativo por parte del hablante que lo profiere. Y ese compromiso colapsa necesariamente en un ordenamiento normativo imperante de todo el discurso práctico: el de la moral crítica. O esto es al menos lo que sostiene Raz. En esto último consiste la llamada "tesis de la unidad del razonamiento práctico" en su versión raziana. ${ }^{8}$

${ }^{7}$ En esta orientación, ya decía Kelsen: “[u]na teoría positivista del derecho se encuentra ante la tarea de buscar entre dos extremos, ambos insostenibles, la vía media correcta. Un extremo es la tesis de que entre la validez, como lo debido, y la eficacia, como un hecho real, no existe relación alguna; de que la validez del derecho es enteramente independiente de su eficacia. El otro extremo es la tesis de que la validez del derecho es idéntica a su eficacia" (Kelsen 2009 [1960], p. 220).

${ }^{8}$ Esta consecuencia se da de un modo sutilmente diverso en el pensamiento de Kelsen dado su relativismo metaético. No es posible detenerse ahora en este punto. En lo que a Raz concierne, cabe decir que para él la operatividad de toda razón depende en última instancia de su justificación moral. Las razones para suscribir esta 
Así, al tiempo que los enunciados internos hartianos —a los que Raz caracteriza como aquellos que llevan a cabo quienes creen en la validez del punto de vista jurídico - conllevarían necesariamente compromiso moral, ${ }^{9}$ los externos — que serían acerca de las creencias y actitudes de los participantes de la práctica - devendrían necesariamente reductivos de los enunciados deónticos a ciertos hechos (Raz 1999 [1975], pp. 171-172). Esta última es una circunstancia que Hart habría estado incluso pretendiendo evitar de modo deliberado, aun si insatisfactorio. Sea como fuere, se trata de una circunstancia que bloquea la posibilidad de aserciones genuinas sobre lo jurídicamente debido. En efecto, dado su compromiso con el externismo/objetivismo de las razones para la acción, ${ }^{10}$ y dada la suscripción de la tesis de la unidad del razonamiento práctico, Raz no puede admitir que alguien postule normas como justificativas de acciones, usándolas como tales, sin expresar en última instancia la creencia en la presencia de una razón moral para la acción. ${ }^{11}$

tesis no son del todo claras en la obra del autor, pero puede decirse aquí que, para él, no se puede exigir la realización de una acción a terceros si ello no se funda, en última instancia, en la creencia de que dicha exigencia está moralmente justificada. Por su parte, esto último consiste en la creencia de que hay una razón operativa para esa acción. A esto se remonta la distinción entre aceptación plena $(f u l l)$ y aceptación débil (weak): Raz 1979d, p. 155; Raz 1998, p. 248.

${ }^{9}$ Véase Raz 1998, donde expresamente se identifican los enunciados committed con los internos hartianos.

${ }^{10}$ Me refiero aquí a la tesis de conformidad con la cual las razones para la acción son hechos, de modo que su presencia o ausencia depende de cómo esté conformado el mundo, siendo los "enunciados de razón” verdaderos o falsos: Raz 1999 [1975], pp. 17-18, Raz 2011, en especial $\S 2$. La atribución de esta tesis a Raz se basa en la distinción entre internismo y externismo según se asuma que las razones para la acción existen, respectivamente, como si necesariamente formaran parte del conjunto subjetivo de consideraciones del agente o bien como hechos objetivos ajenos a todo conjunto de consideraciones objetivas. Sobre el punto, véase Williams 1979 así como Bayón Mohino 1991, § 5.3. Hay otro sentido del todo diverso en que se puede entender esta distinción (internismo/externismo), a saber: el concerniente a la conexión entre las consideraciones de deber y la presencia de razones para la acción. Éste es un sentido en que Raz puede ser calificado de internista ya que para él hay una conexión conceptual entre las consideraciones de deber y la presencia de razones para la acción: como se dijo, para el autor, quien profiere sinceramente un enunciado deóntico expresa su creencia en la presencia de razones morales para la acción. Sobre los dos sentidos de la distinción, véanse Brink 1986 y Redondo 1996, cap. IV, § 3.

${ }^{11}$ De aquí que, rigor de verdad, lo imperioso de rechazar la bipartición hartiana responda - más que a un defecto de la distinción en sí- a la necesidad de compatibilizar las pretensiones del positivismo jurídico normativista con la concepción externista de las razones para la acción que Raz profesa. Sobre esto se avanzará oportunamente. Agradezco a Nicola Muffato por hacerme notar este punto. En este orden de ideas, la única razón por la cual Raz parece rechazar que los detached 
No obstante, sostiene el autor, contrariamente a lo que ese dualismo sugiere, enunciados con idéntica formulación lingüística se usan sensata y constantemente en la práctica, no para decir comprometidamente qué razones para la acción hay, sino para señalar cuál es la situación normativa desde un determinado punto de vista, que podría ser acaso el jurídico, pero no solamente. ${ }^{12}$ Se trata, por ejemplo, de aquellos enunciados acerca de lo que es "jurídicamente" obligatorio según ordenamientos de comunidades desaparecidas, o de enunciados sobre lo que se debe hacer de conformidad con ordenamientos existentes pero no suscriptos por el hablante. Por ejemplo, el no vegetariano que dice a su amigo vegetariano que "no debe comer tal o cual plato por contener carne", ${ }^{13}$ o el católico que dice a su amigo judío ortodoxo qué es lo que debe hacer basándose en su experto conocimiento del contenido normativo del Torá (Raz 1999 [1975], pp. 175-176).

Como es evidente, y como Raz sostiene, éstos serían los únicos enunciados posibles de una ciencia del derecho acorde a las exigencias del positivismo jurídico normativista. ${ }^{14}$ De modo que la ciencia jurídica habría de asumir el punto de vista hipotético del legal man, i.e., de la persona comprometida con, y sólo con, las normas jurídicas: aquella cuyas creencias morales son idénticas a lo que el derecho

sean enunciados internos es que el hablante no expresa al proferir los primeros una aceptación sincera sobre la fuerza vinculante, i.e., no expresa su parecer sobre la presencia de razones para la acción a la luz de un razonamiento práctico asumido como unitario. Aunque hay ciertas ambivalencias en la exposición de Raz, esta afirmación acerca de su pensamiento puede justificarse en pasajes presentes, por ejemplo, en Raz 1998, pp. 248 y ss.; Raz 1999 [1975], pp. 127-128. Especialmente, él sugiere que sólo los enunciados no comprometidos son compatibles con aclaraciones del tipo "pero uno no tiene razón alguna para $\phi "$. Los enunciados internos, luego, serían siempre categóricos —en el sentido de ser la palabra última y pretendidamente correctaacerca de lo que se debe hacer (lo que no quiere decir que sean categóricos como contrapuestos a "condicionales": precisamente consisten en afirmar que bajo tales o cuales condiciones, categóricamente, se debe hacer $\phi$ ). Ésta es la lectura que hace Duarte d'Almeida 2011, p. 179, nota 82 de Raz 1980, nota 30.

${ }^{12}$ Véanse, Raz 1999 [1975], cap. V, § 5.4; Raz 1979d, § 3; Raz 1979b, § 7.

${ }^{13}$ Lo cual no debe llevar a pensar que se trata de una mera transmisión de información empírica (i.e., que el plato tiene carne), sino normativa (i.e., que los vegetarianos no deben comer carne). Este punto lo resalta también Duarte d'Almeida 2011.

${ }^{14} \mathrm{Y}$ así entiende a la visión kelseniana sobre ella: "La ciencia jurídica no se compromete a considerar el derecho como justo. Adopta este punto de vista en un sentido especial de 'adoptar' es una adopción profesional y no comprometida. La ciencia jurídica presupone la norma fundamental no como lo hacen los individuos - i.e. aceptándola como justa-, sino en su especial sentido profesional y no comprometido [... ]" (Raz 1979b, p. 143, citado de Raz 1982, p. 183). 
dispone (Raz 1979b, p. 141; Raz 1998, p. 246). Esto permite enunciar deberes desde el punto de vista de un sistema normativo, incluso a quienes lo aborrezcan moralmente. Tal como Kelsen pensaba:

[t]ambién un anarquista, como jurista, puede describir un derecho positivo como un sistema de normas válidas, sin aprobarlo. Algunos libros de texto en que se describe un sistema de normas constitutivo de obligaciones, facultamientos, derechos y competencias, fueron escritos por juristas que menospreciaban políticamente esos órdenes jurídicos. (Kelsen 2009 [1960], p. 229, nota 133) ${ }^{15}$

¿Dónde habría de situarse la divergencia entre este "tercer tipo" de enunciados y los internos-comprometidos? A primera vista, la diferencia aparecería como ubicada a nivel pragmático, sobre la base de la consideración de que aquellos son los proferidos por quienes "no están primordialmente ocupados en aplicar el derecho a ellos mismos o a otros, sino en advertir a otros lo que deben hacer de conformidad al derecho" (Raz 1979d, p. 155; citado de Raz 1982, p. 198, resaltado propio).

Un enunciado jurídico imparcial [a detached legal statement] es un enunciado sobre el derecho, sobre qué derechos u obligaciones jurídicas tienen los individuos, no un enunciado sobre las creencias, actitudes o acciones de los individuos ni tampoco acerca de sus creencias, actitudes o acciones hacia el derecho. Sin embargo, un enunciado normativo imparcial no contiene la fuerza normativa completa de un enunciado normativo ordinario. Su emisión no compromete a quien lo dice a las opiniones normativas que su dicho expresa. (Raz 1979d, p. 153. Citado de Raz 1982, p. 196)

${ }^{15}$ Como es evidente, y tal como Raz reconoce, los enunciados no comprometidos tienen como antecedente inmediato a los Rechtssätze kelsenianos, si no se identifican sin más con ellos. Concretamente, para el autor praguense los enunciados jurídicos "son proposiciones condicionales que expresan que, conforme a un orden jurídico, nacional o internacional, dado al conocimiento jurídico, deben producirse ciertas consecuencias determinadas por ese orden, bajo determinadas condiciones que el orden jurídico determina" (Kelsen 2009 [1960], p. 84). Y lo que distingue a estos "enunciados" de otros es su específica función: "No interesa, con todo, la forma lingüística adoptada, sino el sentido del acto que instaura la norma, que produce derecho. $\mathrm{Y}$ el sentido de ese acto es distinto del sentido del enunciado descriptivo del derecho. En la diferenciación entre enunciado jurídico y norma jurídica se expresa la distinción entre función del conocimiento jurídico, y la función, enteramente distinta, que cumple la autoridad jurídica representada por órganos de la comunidad jurídica" (Kelsen 2009 [1960], p. 86). 
Así, la distinción residiría en los distintos usos a que el mismo acto locucionario podría destinarse. ${ }^{16}$ De modo que, en rigor de verdad, no se trata de dos tipos de enunciados sino más bien de dos tipos de actos de habla, y la diferencia entre uno y otro reposa en la fuerza ilocucionaria con que se profieren. ${ }^{17}$ Cuando se profieren enunciados deónticos para justificar, criticar o exigir la realización de ciertas acciones o conductas, estamos ante la expresión de un compromiso práctico. Por el contrario, cuando se profieren los mismos enunciados para informar, describir, alertar, aconsejar, etc., estamos ante la expresión de un compromiso con una mera hipótesis acerca de la validez de un punto de vista desde el cual se vislumbra una situación normativa (se adhiera o no al punto de vista desde el cual se profiere la enunciación). En todo caso, para Raz sólo es posible proferir enunciados deónticos informativos//que informen si se adopta hipotéticamente el punto de vista de los moralmente comprometidos qua (moralmente) válidos.

A esto último apunta la objeción de Duarte d'Almeida, que alega precisamente la irrelevancia de la asunción de un punto de vista cualquiera con fines informativos, sea en términos de compromiso moral, o en cualquier otro. Esta irrelevancia anularía sin más el cometido de los enunciados no comprometidos. En efecto, la utilidad de un acto de habla tal radicaría en la posibilidad de proporcionar a los oyentes información de la que éstos carecieran y que no sería posible transmitir sin asumir el punto de vista en cuestión. Sería entonces crucial que hubiera una relación determinante entre el con-

${ }^{16}$ Véase una lectura en términos de actos ilocucionarios de la distinción de Raz, entre enunciados comprometidos y no comprometidos, en Shiner 1992, pp. 137 y ss. Sobre este modo de concebir la relación semántica/pragmática, véanse Hart 1966, p. 136, Hart 1982, p. 136. En rigor, la cuestión es dudosa en la obra de Raz. Por empezar, no se sigue obviamente de la distinción entre enunciados comprometidos y no comprometidos, que los primeros se profieran siempre (pragmáticamente) para justificar acciones: en la teoría raziana parecen perfectamente concebibles proferencias de enunciados comprometidos donde el hablante simplemente informe sobre qué razones para la acción hay, sobre qué debe hacerse desde el punto de vista que él suscribe. Una opción sería entender que la diferencia que Raz pretende trazar entre enunciados comprometidos y detached ha de situarse en el plano semántico. Indicios en esta dirección se encuentran en Toh 2007, p. 413, e incluso en Duarte d'Almeida 2011, p. 179. Cfr. Muffato 2009, p. 611. Esta discusión excede, de todos modos, las posibilidades de este trabajo.

${ }^{17}$ Así, Redondo 1996, p. 124. En este sentido, los actos de habla consisten, en rigor de verdad, en proferir enunciados; i.e., son enunciaciones. En lo que sigue hablaré de todos modos de "enunciados no comprometidos" dada la usanza en las discusiones sobre el tema. Para estas nociones véanse Austin 1975, Searle 2001 [1969]. 
tenido implicado en la asunción del punto de vista de que se trate (por caso, el jurídico) y el contenido del enunciado que desde allí se profiere. $^{18}$

Al contrario, sería "pragmáticamente inútil" [pragmatically pointless] proferir un enunciado asumiendo un punto de vista si esa asunción no cambiase en absoluto las condiciones de verdad del enunciado en cuestión, o bien si esa asunción agotase el contenido de cuanto se enuncia. En otras palabras, la adopción del punto de vista jurídico, para ser relevante, tendría que ser parte de las condiciones de verdad del enunciado jurídico, pero no agotarlas; y podría transmitir a un participante de la práctica información normativa que no posea por el solo hecho de ser un aceptante comprometido. Volviendo a los otros ejemplos, si asumir el punto de vista moralmente comprometido del judío ortodoxo no cambiase en absoluto el contenido del enunciado de deber por medio del cual el católico experto en el Torá procura informar a su amigo sobre los deberes religiosos que - como judíotiene, o bien si esa asunción fuere todo cuanto se transmite, la asunción sería superflua. Y, para Duarte d'Almeida, esto es precisamente lo que ocurre al asumir el punto de vista del legal man (o del comprometido moralmente con el sistema que fuere), de modo que los enunciados no comprometidos son pragmáticamente inútiles.

Creo que, en un sentido relevante, éste es el mismo tipo de argumento que Ross desarrolló sobre la inutilidad de la presuposición kelseniana de una norma fundante de la validez (i.e., fuerza obligatoria) de un ordenamiento: "[l]a afirmación de que un orden jurídico posee validez o fuerza obligatoria nada nos dice acerca de obligaciones o hechos jurídicos sino que expresa nuestras obligaciones morales" (Ross 2014 [1961], p. 17).

El punto de Ross en su popular crítica a Kelsen enfatizaba que sólo se puede obedecer la norma presupuesta (i.e., "se debe obedecer el derecho") llevando a cabo la conducta de la norma jurídica "validada" por la presuposición. Y para saber qué es lo que esta norma exige es del todo superfluo presuponer una norma fundante. La analogía está en el hecho de que Duarte d'Almeida apunta precisamente a la inutilidad de asumir el punto de vista según el cual, e.g., "se debe obedecer el Torá" para saber e informar acerca de

18 "Ya que la idea de un enunciado formulado desde un punto de vista parece implicar que la evaluación sobre la verdad o la falsedad del enunciado es relativa al punto de vista adoptado, ello parece implicar que desde el punto de vista $x$ un enunciado token puede ser aseverado como verdadero, mientras que desde el punto de vista $y$ puede presentarse como falso" (Duarte d'Almeida 2011, p. 184; traducción propia). 
"qué es lo que según el Torá se debe hacer". Para obedecer el Torá o el derecho alcanza con saber qué es lo que las normas del Torá o del derecho exigen. Que se debe obedecer el Torá o el derecho es algo que el judío ortodoxo o el legal man ya "saben" precisamente porque se sigue sin más de sus convicciones morales, de $s u$ punto de vista.

\section{El punto de vista jurídico}

Esto último pone de manifiesto que detrás del argumento de la inutilidad pragmática del dispositivo raziano hay ciertos presupuestos tan decisivos como controvertibles. En efecto, en el texto citado Duarte desarrolla un argumento independiente pero de algún modo más profundo y prioritario frente al que desacredita los enunciados no comprometidos por considerarlos pragmáticamente estériles. Ese argumento se dirige lisa y llanamente a rechazar el problema mismo que Raz postuló. Para el autor, como para muchos otros entre los que cabría incluir a Ross, asumir el punto de vista jurídico, o no hacerlo, no produce diferencia alguna con respecto al tipo de información que se ha de obtener y transmitir en relación con el contenido normativo de un ordenamiento (Duarte d'Almeida 2011, p. 189). Sencillamente ciertos hechos sociales determinan cuáles son las exigencias del derecho y no se requiere adoptar punto de vista alguno para acceder a esa información y transmitirla neutralmente (Duarte d'Almeida 2011, p. 193).

El argumento de Duarte d'Almeida se basa en dos tipos de consideraciones. La primera apunta, en consonancia con el pensamiento de muchos otros autores, entre ellos Eugenio Bulygin, a que de una disposición normativa, por caso un texto legislativo, que rece

(DN1) Prohibido $\phi$,

disposición que funge como material jurídico fuente de normas jurídicas, se obtienen enunciados de deber jurídico verdaderos o falsos, sin que sea necesario para ello adoptar punto de vista alguno. Así, a partir de DJ1 se sigue, sin más, que (es verdad que):

(EJ1) el derecho exige [requires] que todos se abstengan de hacer $\phi$.

La segunda serie de consideraciones apunta al rechazo de la tesis semántica raziana, basándose en una aparente evidencia de diversidad de significado de los términos deónticos usados en el ámbito jurídico 
con respecto a los mismos términos usados en el contexto moral (o en otros contextos normativos). Propongo revisar primero este segundo argumento a efecto de postular algunas dudas y pasar posteriormente al tratamiento de la primera serie de consideraciones. Son estas últimas las que en rigor de verdad permiten reformular el problema y dotar de cierta relevancia a la necesidad de adopción de un punto de vista jurídico con fines informativos. En este último sentido, creo que las observaciones de los críticos conducen a pensar, más que en un rechazo, en la necesidad de una reinterpretación del problema: si bien parece correcto descartarlo en el modo en que Raz lo plantea, siguen quedando en apariencia cuestiones irresueltas.

\subsection{El carácter inofensivo de la tesis semántica}

El problema que Raz se postuló y que lo condujo a la búsqueda de "enunciados no comprometidos" quedaría descartado si se elimina una de sus premisas de partida: la de la identidad de significado de los términos deónticos en todo contexto. Duarte d'Almeida ha sostenido que la falsedad de esa premisa es evidente dada la plausibilidad de afirmar con pleno sentido que el derecho requiere de alguien la realización de $\phi$, pero que contemporáneamente esa persona no tiene razón alguna para (deber alguno de, obligación alguna de, etc.) hacer $\phi$.

Asumamos que efectivamente los enunciados que afirman qué es lo que el derecho exige o requiere (que por lo demás quedarían en principio fuera de la preocupación raziana de dar cuenta del uso de lenguaje normativo) son traducibles en términos deónticos, y son por lo tanto equivalentes:

(EJ1) El derecho exige [requires] que todos se abstengan de hacer $\phi \ldots$

(EJ2) Todos tienen el deber jurídico de abstenerse de hacer $\phi \ldots$

(EJ3) Todos tienen la obligación jurídica de abstenerse de hacer $\phi \ldots$

(EJ4) Jurídicamente todos deben abstenerse de hacer $\phi \ldots$

Todos estos enunciados, verdaderos o falsos de conformidad con cuanto se pretende, son obviamente compatibles con afirmaciones posteriores que podrían complementarlos, como, por ejemplo:

... y por lo tanto todos tienen el deber de (o razón para, o la obligación de) abstenerse de hacer $\phi$, 
así también con otras tales como:

... pero nadie tiene el deber de (o razón para, u obligación de) abstenerse de hacer $\phi$.

Ni los complementos del primer tipo serían redundantes, ni serían contradictorios los del segundo, lo que demostraría que la tesis según la cual términos como "derechos" y "deberes" son usados con el mismo significado en los contextos jurídico y moral sería lisa y llanamente falsa. ${ }^{19}$

No obstante, creo por un lado que este argumento es de por sí insuficiente para demostrar que los términos deónticos poseen distinto significado cuando se usan en uno u otro contexto normativo. Pero, por otro lado, creo que demostrarlo es además innecesario. ${ }^{20}$ Lo primero se debe a que del hecho de que dos "deberes" posean distintos parámetros de justificación no se sigue que el significado del término "debe" cambie cuando se refiere a uno u otro parámetro. Obsérvese, análogamente, que parece perfectamente posible afirmar que:

(EF1) desde el punto de vista de la teoría ptolemaica, es verdad que los astros giran alrededor de la Tierra; sin embargo, no es en absoluto verdad que así funcione el universo.

La sensatez de este enunciado no tiene por qué conducirnos a la conclusión de que el significado de "verdad" ptolemaico y el propio son distintos. Algo parecido, puede sostenerse, sucede en relación con la cuestión de los estándares de prueba de enunciados fácticos en contextos jurídico-procesales (o quizás incluso en cualquier contexto

19 "Lo que esto ilustra es simplemente que [...] hay un uso del lenguaje sobre ‘derechos' y 'deberes' en enunciados jurídicos que es, por lo demás, el uso característico y extendido en el contexto jurídico, en el cual esos términos poseen un sentido completamente distinto del que tienen en el 'contexto moral' " (Duarte d'Almeida 2011, p. 198; traducción propia).

${ }^{20}$ Claro que Raz tendría todavía una estrategia para rechazar tanto el argumento de Duarte D'Almeida, cuanto el alegato de innecesariedad que aquí se ha efectuado. Así, dadas sus teorías de las razones para la acción, las razones protegidas y la autoridad, para él no tendría sentido decir que "jurídicamente es obligatorio $\phi$, pero no hay ninguna razón para hacer $\phi$ ". Para él, "jurídicamente se debe hacer $\phi$ " y "la autoridad ordenó $\phi$ " son, en efecto, intercambiables. La justificación de esta intercambiabilidad remite a su concepción de la autoridad legítima, y es esto lo que señala Muffato 2013 al indicar que el argumento de Duarte D'Almeida depende de una discusión más profunda que ponga en crisis a la metaética raziana. He pretendido evitar hacer esto en este trabajo. 
epistémico). Uno puede decir que cierto enunciado fáctico es aceptable como verdadero en un contexto y que no lo es en otro, o que es falso tout court. Así:

(EF2) según (el estándar de prueba de) el derecho procesal civil italiano es verdad que Silvio Berlusconi llamó por teléfono a la comisaría durante la madrugada del día $d$, pero de conformidad con (el estándar de prueba de) el derecho procesal penal italiano ello no es verdad.

De esto no se sigue que los conceptos de "verdad" empleados sean distintos en cada contexto probatorio, y de hecho parecería que no es así. La cuestión es que divergen los estándares de justificación o aceptabilidad. Y esto no tiene por qué ser diferente en lo que respecta a la justificación de la presencia de un deber según distintos ordenamientos o sistemas normativos. Pace la tesis de la unidad del razonamiento práctico, no veo por qué una acción no pueda estar permitida, prohibida o ser obligatoria según un sistema y no estarlo o serlo desde la perspectiva de otro, sin que los términos deónticos cambien de significado o sentido. ${ }^{21} \mathrm{Y}$ de aquí que el esfuerzo por rechazar la premisa resulte además innecesario.

En efecto, el problema no es tanto que Raz crea que los términos deónticos tienen el mismo significado en contextos morales y jurídicos, sino que considere que ambos deben estar justificados en última instancia del mismo modo, por el mismo tipo de razones. Pero el rechazo de esto último, que permite enunciados sensatos como los puestos bajo consideración (i.e., "jurídicamente se debe $\phi$ pero no se debe $\phi ")$, no entraña de por sí que "debe" tenga dos significados distintos. En este punto, la cuestión semántica parece efectivamente

${ }^{21}$ Por cierto, el rechazo de la tesis de la unidad del razonamiento práctico requiere una argumentación considerablemente más potente que no puede siquiera intentarse aquí. Esto es así, en especial, dada la amplia y favorable recepción de la tesis en la filosofía del derecho. Véanse, por ejemplo, Bayón Mohino 1991, Bayón Mohino 2000, Garzón Valdés 1993, Nino 1985, Nino 1993, Nino 1994, Ruiz Manero 1990, pp. 178179. Véase un rechazo fundado de la tesis, al que remito para estos fines, en Redondo 1996, pp. 239-251. Uno de los dictámenes anónimos plantea una pregunta acerca de si el positivismo jurídico que acepta la tesis semántica reduccionista queda necesariamente comprometido a atribuir distintos significados a los términos normativos (e.g., "obligación", "deber", etc.) cuando aparecen en contextos morales y jurídicos. La respuesta a este cuestionamiento es que no. Pero si el reduccionista suscribe además la tesis de la unidad del razonamiento práctico, y si es consistente, se verá entonces obligado a renegar del uso de estos términos en el discurso auténticamente teórico. 
no problemática, pero siempre que se rechacen los presupuestos metaéticos razianos, tal como aquí se ha hecho de un modo preliminar.

De todas maneras, y aquí radica lo crucial para los efectos de este trabajo, que se trate todavía de un falso problema depende de que conocer las condiciones de justificación estrictamente jurídicas de ciertos deberes no requiera la adopción de punto de vista o postura normativa alguna. ¿Es esto así?

\subsection{Enunciados jurídicos y existencia de normas}

Volvamos a la primera serie de consideraciones antes mencionadas. Según esta postura, a partir de una disposición normativa como DJl se obtendría sin problemas un enunciado jurídico informativo, verdadero o falso como EJl.

Adoptando nuestros métodos interpretativos ordinarios, [EJ1] sería no problemáticamente considerado un enunciado verdadero del derecho. Se torna claramente verdadero sólo en virtud del contenido de los materiales, y de hecho no hace más que enunciar el contenido del conjunto de fuentes materiales sobre las que versa. Ciertamente no es un enunciado de una razón para la acción. No se profiere desde punto de vista en particular alguno". (Duarte d'Almeida 2011, p. 195; traducción propia)

Como se dijo, este argumento está fuertemente ligado al abordado en precedencia, tendiente a demostrar el carácter no informativo de los enunciados no comprometidos. De hecho, parecería ser un presupuesto decisivo para afirmar que, descartada la relevancia de la asunción del punto de vista como hipótesis de validez (i.e., como fuerza vinculante moral), dicha asunción es irrelevante tout court.

La relevancia de esa asunción dependería, como se dijo, de que el contenido que entraña fuera parte, pero sólo parte y no la totalidad, de lo que hace verdadero al enunciado. No obstante, se decía, la adopción del punto de vista jurídico en términos de hipótesis de validez (i.e., fuerza vinculante hipotética) por el no aceptante-comprometido parecería ser siempre irrelevante, así como insuficiente, en relación con el aspecto informativo que es la cuestión crucial. La adopción, por parte del católico, del punto de vista judaico ortodoxo según el cual lo que diga el Torá es moralmente vinculante parecía carecer efectivamente de significación para que aquel pudiera informar sobre lo que el Torá exige hacer. Y lo mismo sucedería en relación con el derecho: la asunción del punto de vista jurídico en términos de fuerza vinculante del derecho nada aportaría si lo que se pretende 
es adquirir o transmitir información acerca de cuál es el contenido normativo jurídico específico, sobre cuáles son las acciones que el ordenamiento jurídico requiere.

Esta conclusión se acerca a la que defendió hace ya muchos años Eugenio Bulygin. Casi inmediatamente después de que Raz los trajese a colación y procurase situarlos en el centro de la escena iusfilosófica, Bulygin condenó los enunciados no comprometidos sosteniendo que no elucidan aspecto especial alguno del discurso normativo-jurídico (Bulygin 1991b [1981]). Para él, en la medida en que estos últimos se identifiquen con los enunciados jurídicos kelsenianos, tal como Raz pretende, pues se identificarán también con los enunciados externos menos extremos hartianos. ${ }^{22}$

Dejando al margen cualquier diferencia que pueda haber entre posturas como las de Bulygin y Duarte, lo cierto es que ambas asumen que es perfectamente posible establecer qué es lo que según el ordenamiento en cuestión debe hacerse sin adoptar punto de vista alguno. Y en ambos casos parece que ello consiste sólo en identificar qué normas existen en ese ordenamiento. Utilizando el ejemplo del católico experto en ley rabínica que informa al amigo judío ortodoxo de su situación normativa desde el punto de vista de este último, dice Duarte:

Evidentemente, la posesión de una información de este tipo [sobre lo que debe hacerse según el Torá] no proviene simplemente del hecho de que uno sea un judío ortodoxo. Pero en ese caso, y precisamente por ello, parecería, el amigo católico no necesita adoptar el punto de vista judío ortodoxo para obtenerla. (Duarte d'Almeida 2011, p. 186; la traducción y las cursivas son mías.)

Ahora bien, de que la información no se obtenga solamente por asumir o compartir el punto de vista, de que esto no sea condición suficiente, no se sigue todavía que la asunción no sea condición necesaria para tener dicha información. Aun cuando ello no signifique, como Raz pretende, que el punto de vista que es necesario asumir

${ }^{22}$ Éstos, por su parte, constituirían en rigor formulaciones elípticas de enunciados condicionales: el no vegetariano estaría diciendo a su amigo que "si quiere obedecer a las reglas del vegetarianismo, no debe comer tal o cual plato" (Bulygin 199lb [1981], p. 437). Véase también, en esta orientación, Guastini 2004, § 4 (i). En verdad, Raz rechazaba expresamente y de antemano esta iniciativa aunque en términos sumamente oscuros: Raz 1999 [1975], p. 173. Para un análisis de este argumento, y de su "blindaje metaético" ante las críticas citadas, véase Muffato 2013, especialmente $\S 3.2$. 
sea uno de los moralmente comprometidos. Descartado esto último, creo que todavía hay al menos dos cuestiones que dejan abierta la discusión sobre la necesidad de adoptar el punto de vista jurídico a fin de emitir enunciados informativos sobre lo que según el derecho se debe hacer. La primera tiene que ver con el significado de los enunciados de deber jurídico (en términos de condiciones de verdad), y con la relación que ello guarda con la existencia de normas jurídicas. La segunda tiene que ver con la existencia misma de dichas normas, cualquiera que sea la relación que guarde con los enunciados bajo consideración.

\section{Enunciados jurídicos y proposiciones normativas}

En 1982 Hart criticaba la teoría imperativista del derecho diciendo que no lograba dar cuenta de un rasgo crucial de los enunciados que estamos tratando, y que caracterizaba allí como enunciados de obligación jurídica [statements of legal obligation]:

este rasgo es lo que ahora se denomina "normatividad" de tales enunciados y de los enunciados del derecho o sobre la posición jurídica de individuos sujetos al derecho. Decir que un hombre tiene una obligación jurídica de llevar a cabo cierto acto no es, aunque puede implicar, un enunciado acerca del derecho o un enunciado relativo a que el derecho existe y le exige comportarse de determinado modo. Es más bien evaluar su actuar o no actuar de ese modo desde el punto de vista adoptado al menos por las cortes del sistema jurídico que aceptan el derecho como estándar de guía y evaluación de la conducta, determinando lo que está permitido por medio de demandas y presión a la conformidad. Dichos enunciados no son enunciados históricos o fácticos descriptivos de acciones, actitudes o creencias pasadas, presentes o futuras, ni de sujetos ni de funcionarios del sistema jurídico, sino que son enunciados sobre lo que los individuos deben o no deben hacer jurídicamente; de manera análoga, los enunciados sobre los derechos jurídicos son enunciados acerca de lo que los individuos tienen la facultad de hacer o de no hacer o de exigir o prohibir a otros. Semejantes enunciados normativos son la forma más común de establecer el contenido del derecho, en relación con cualquier materia, por parte de ciudadanos ordinarios, abogados, jueces u otros funcionarios, y también por parte de juristas y profesores de derecho en relación con su propio sistema jurídico u otro distinto. (Hart 1982, p. 145; traducción propia)

Pablo Navarro ha negado que la distinción entre enunciados del derecho [of the law] y enunciados acerca del derecho [about the law], que Hart introdujo en este pasaje, se corresponda con su más antigua 
distinción entre enunciados internos y externos. Por el contrario, ambos serían tipos de enunciados externos, pero sólo los segundos serían enunciados históricos o fácticos. Los enunciados del derecho, en contraste, serían enunciados externos sobre lo que debe o no debe hacerse jurídicamente, como el modo más adecuado para determinar cuál es el contenido del derecho (Navarro 2012a, p. 19). ${ }^{23}$ Estos enunciados, dice Navarro, no entrañarían aceptar ninguna regla en absoluto: "[a]l menos parece extraño suponer que un profesor de derecho que informa sobre el contenido de un sistema jurídico extranjero lo hace mediante enunciados internos que expresan su aceptación de las pautas en cuestión" (Navarro 2012a, p. 20). ${ }^{24}$

Eugenio Bulygin, como se dijo, ha sido un consistente defensor de la tesis según la cual enunciados tales son la versión menos extrema de los enunciados externos de Hart, ${ }^{25}$ idénticos también a los Rechtssätze kelsenianos (pace Raz) y equivalentes contemporáneamente a lo que von Wright denominó normative statements (von Wright 1963, p. 106). Pero ¿en qué consisten esos enunciados?

Bulygin ha sostenido, al menos durante buena parte de su producción académica, que este tipo de enunciados no habrían de considerarse más que sinónimos de proposiciones normativas: aserciones acerca de la existencia de normas jurídicas. De modo que "lo que von Wright llama 'enunciados normativos' [normative statements] no son más que proposiciones normativas disfrazadas" (Bulygin 2003; p. 81, Bulygin 2007, p. 150), y los primeros quedan reducidos a las segundas por una relación de identidad. ${ }^{26}$

Ahora bien, qué signifique que una norma jurídica existe es una cuestión sumamente trillada, pero en la medida en que ello consista

${ }^{23}$ Sobre la identificación entre los enunciados externos de Hart y las proposiciones jurídicas de Kelsen, en contra de Raz, véase Bulygin 1991b [1981], p. 433.

${ }^{24}$ En contra, Toh considera que la distinción hartiana entre statements of law y statements about law es idéntica a la distinción entre enunciados internos y externos y que ésta, a su vez, es una manifestación de la distinción kantiana entre punto de vista deliberativo y punto de vista teórico. Véase Toh 2007, p. 408, nota 13.

${ }^{25}$ Véase Hart 2012 [1961], pp. 89-90, 242, y especialmente la nota a la p. 86 en la p. 291. En el mismo sentido, Hart 1983, p. 14, Hart 2012, p. 242. Sin embargo, se ha dicho, "Hart es culpable de una omisión, no dice qué pasa si el observador es menos extremo y usa enunciados externos del tercer tipo" (Bulygin 1991 [1981], p. 183). Y esto es, precisamente, lo que Bulygin asume como perfectamente posible.

${ }^{26} \mathrm{Si}$ además se entiende que la existencia de normas se reconduce a prescripciones de la autoridad, los enunciados de deber jurídico colapsarán en concepciones parecidas a las de Bentham y Austin, acaso con la corrección que Duarte d'Almeida sugiere respecto a esas posturas tradicionalmente tachadas de "reductivistas". Véase Duarte d'Almeida 2011, § 3 D, y en especial la nota 121 . 
en una propiedad empírica, entonces los enunciados jurídicos quedarán convertidos en enunciados acerca del derecho, i.e., quedarán reducidos a ellos. Esto es lo que enfatiza Navarro, señalando que hay una diferencia en el modo en que autores como Alchourrón y Bulygin conciben los enunciados de deber jurídico, frente a otros exponentes del positivismo jurídico como, por ejemplo, Kelsen, Hart o Raz. Para estos últimos, la relación entre enunciado jurídico y proposición normativa no sería de identidad, sino más bien de fundamento.

En este orden de ideas, un enunciado como EJl se entiende, según Alchourrón y Bulygin, al menos en principio, como si significara exactamente lo mismo que:

(PN1) existe una norma en el ordenamiento OJ que prohíbe $\phi$.

En contraste, desde la segunda perspectiva, un enunciado de este tipo parece más bien dar sustento a EJl, no identificarse con él. Navarro ha mostrado en esta orientación que la tesis de la identidad resulta insatisfactoria, dado que si EJl significase lo mismo que PN1, serían entonces sustituibles; mas la sustitución acarrea dos consecuencias sumamente contraintuitivas:

(a) La relación de fundamento que parece haber entre norma y enunciado jurídico deviene en una tautología: ya no "está prohibido $\phi$ porque hay una norma que prohíbe $\phi$ ", sino que "hay una norma que prohíbe $\phi$, porque hay una norma que prohíbe $\phi$ ".

(b) En el razonamiento jurídico, la premisa mayor suele formularse en términos condicionales, y ello permite pasar por modus ponens a la conclusión, con sólo invocar un caso individual, instancia del antecedente de la norma, como premisa menor. Si esa premisa se sustituyese con una proposición normativa (que será formulada no condicionalmente), tal como la tesis de la identidad debiera admitir, el razonamiento quedaría bloqueado. ${ }^{27}$

En suma, si los dos enunciados significasen lo mismo, serían sustituibles, pero, como surge de estos dos comentarios, EJI no parece sensatamente sustituible con PN1.

${ }^{27}$ Estos argumentos se desarrollan en Navarro 2012a. Véanse también Navarro 2012b y Navarro 2016. Se podría decir que cuando el "enunciado de deber jurídico" aparece como premisa en el razonamiento práctico, no funge de enunciado descriptivo en absoluto, sino de norma, con lo cual no funcionaría el argumento de la sustituibilidad. Pero si el enunciado se profiriese informativamente, y fuera por lo tanto sustituible, también parecería habilitar inferencias: el informado podría inferir "si todos deben hacer $\phi$ según OJ, luego, $X$ debe hacer $\phi$ en OJ". En cualquier caso, este segundo argumento — que requeriría una discusión más profunda - puede ser dejado de lado en lo que sigue. 
Esto ha llevado a Bulygin a conceder que predicar la identidad de significado entre enunciados normativos y proposiciones normativas sea "probablemente una exageración", aunque sin claudicar de lo que ahora pasa a denominar "equivalencia material" entre ellos (Bulygin 2003, pp. 81-82). ${ }^{28}$ Él sostiene, tomando especialmente en consideración los comentarios de von Wright acerca de la práctica de alegar una proposición normativa como fundamento justificativo de un enunciado jurídico, que este último habría sido víctima de la ambigüedad sistemática de las oraciones deónticas. Así, el tipo de respuesta según el cual se debe hacer $\phi$ porque hay una norma que impone $\phi$ sólo tendría sentido, piensa Bulygin, frente a enunciados normativos (entendidos como enunciados internos). Esto es así, dado que quien invoca la existencia de la norma estaría además prescribiendo (en general tácitamente) que esa norma debe ser obedecida.

La innecesariedad de suscribir esta prescripción, se recordará, constituía los cimientos del argumento - sea en la versión de Duarte d'Almeida, sea en la de Ross - según el cual la asunción de un punto de vista, o la presuposición de validez de una norma fundante básica, es innecesaria. Tal como se ha visto, desde esta perspectiva es suficiente saber que el derecho exige $\phi$, no importa si la exigencia debe o no ser satisfecha (desde algún punto de vista no jurídico). Y para saber qué es lo que el derecho exige no hace falta asumir esto último en sentido alguno.

Sin embargo, creo que lo anterior es todavía insuficiente para rechazar la relevancia de asumir un punto de vista en términos de compromiso normativo. Ante todo, vale la pena recordar que el objetivo atribuido a una hipotética teoría del derecho de corte positivistanormativista era dar cuenta de lo que jurídicamente debe hacerse. Que la sola existencia de normas jurídicas (o incluso, si se prefiere, de prescripciones de la autoridad) haga verdaderos o falsos a los enunciados sobre lo que jurídicamente debe hacerse depende, en rigor, de que sea el caso que en la práctica jurídica, para los participantes, ello sea condición necesaria y suficiente del deber jurídico. Pero lo cierto es que la sola existencia de una norma no parece garantizar en absoluto que lo que ella prescribe deba ser llevado a cabo jurídicamente. Después de todo, como mínimo, la jerarquía - meramente jurídicaentre normas es tan determinante como la propia existencia de ellas

${ }^{28}$ Véase especialmente la nota 3. 
para desentrañar lo que debe hacerse según el derecho. ${ }^{29}$ De modo que siendo la existencia de normas sólo una condición (que podemos conceder como) necesaria, mas no ya una condición suficiente del deber, también la equivalencia material parece insostenible. Precisamente por ello se nos presenta como perfectamente sensata la afirmación de un abogado hipotético según la cual:

(EJ5) Existe una norma en el ordenamiento OJ que prohíbe $\phi$ (PN1); pero nadie tiene el deber jurídico (la obligación jurídica, razón jurídica) en $\mathrm{OJ}$ de abstenerse de $\phi .^{30}$

Elucidar qué otras condiciones, además de la existencia de normas jurídicas, hacen que lo que éstas disponen deba ser llevado a cabo jurídicamente, entre las cuales están las relaciones de jerarquía aunque quizás no sean las únicas, parece exigir manipular los criterios normativos que determinan, en la práctica jurídica efectiva, qué es lo que jurídicamente se debe hacer.

Obsérvese que el problema no es si la norma jurídica debe ser obedecida - o si el derecho en su totalidad debe ser obedecido-, como juicio externo de fuerza vinculante, por caso un juicio moral. Diversamente, la cuestión que ahora se pone bajo consideración es determinar si lo que la norma jurídica efectivamente existente dispone - por caso, hacer $\phi$ - es lo que jurídicamente debe hacerse, sólo tomando en consideración criterios internos, parámetros estrictamente jurídicos. Recurriendo a los distintos sentidos que Ross ha atribuido al término "validez", podría decirse que el primero de los problemas remite a "validez" como juicio ético: en términos de fuerza obligatoria del derecho. Lo segundo, en cambio, concierne al problema de la validez como "función interna, en el sentido de que afirmar que un acto es válido es afirmar algo según un sistema de normas dado. El enunciado es un juicio jurídico que aplica reglas jurídicas a determinados hechos" (Ross 2014 [1961], p. 23).

En conclusión, contar con información sobre qué normas forman parte del ordenamiento jurídico es todavía insuficiente para afirmar que tal o cual cosa debe ser llevada a cabo jurídicamente: para ello es indispensable tomar posición con respecto a las jerarquías normativas, lo cual presupone atribuir significado a los postulados jurídicos

${ }^{29}$ Véase Navarro 2012a, p. 24, sobre la base de ciertas consideraciones de Alchourón (1991), para quien la obligatoriedad está determinada por dos elementos: el contenido normativo y la jerarquía de normas.

${ }^{30}$ Caracciolo 2013, p. 41, hace una sugerencia en esta dirección echando mano de la estrategia de "la pregunta abierta" de Moore. 
relevantes. En efecto, la insuficiencia del catálogo de normas existentes para determinar cuáles son los deberes jurídicos constituye sólo parte del problema, ya que todavía ha de vislumbrarse cuándo se configura jurídicamente esa condición necesaria, aunque no necesariamente suficiente, para la determinación del deber jurídico: queda pendiente la pregunta acerca de en qué consiste la existencia de una norma jurídica, en qué consiste la existencia de una norma dentro de un ordenamiento jurídico si ello no fuere lo mismo y, por lo tanto, cuáles son las condiciones de verdad de las proposiciones normativas.

\section{Existencia de normas jurídicas y punto de vista interno}

La única posibilidad de sostener la tesis según la cual los enunciados jurídicos son descriptivos al tiempo que se identifican con proposiciones normativas, o son materialmente equivalentes a ellas, o están fundamentados en todo o en parte por ellas, requiere tener una concepción de estas últimas que no se identifique con lo que Guastini ha denominado tesis deóntica: aquella que dice que las proposiciones normativas entrañan un juicio de validez como fuerza vinculante de las normas "mencionadas". 31 Si así fuere, las proposiciones normativas habrían devenido ellas mismas "preceptos reiterados" y el problema originario concerniente a los compromisos morales involucrados en los enunciados de deber jurídico habría vuelto a nosotros después de un largo rodeo. ${ }^{32}$

Para evitar este inconveniente, muchos autores han buscado aferrarse a conceptos descriptivos de "validez". Se ha intentado determinar de tal modo las condiciones de existencia de normas jurídicas sobre la base de criterios empíricos. Para muchos, esto permitiría además, según se ha visto en el parágrafo precedente, determinar las condiciones de verdad de los enunciados de deber jurídico "informativos", en la medida en que éstos se entiendan como sinónimos de proposiciones normativas.

Desde esta óptica, si bien una teoría del derecho podría no tener - y de hecho no tiene por qué tener- una respuesta frente a la cuestión de la fuerza vinculante, ni una para resolver el problema de la aplicación del derecho por parte de la autoridad, podría responder,

\footnotetext{
${ }^{31}$ Véase Guastini 2013c. Vale la pena recordar que, como Guastini afirma, en rigor, la proposición normativa es el contenido de un enunciado, no el enunciado en sí. Aquí se ha utilizado la terminología habitual en la que se denomina al enunciado (asertivo de la existencia de una norma) por su contenido (la proposición según la cual la norma existe). Cfr. también Guastini 2000.

${ }^{32}$ Véase Scarpelli 1967 y, en el mismo sentido, Bulygin 199la [1982].
} 
sin problemas y sin tener que asumir punto de vista alguno, a la pregunta por la identificación del derecho: "la identificación de las normas que lo integran $y$, en consecuencia, de las obligaciones que impone a los sujetos jurídicos en general y a los jueces en particular" (Bulygin 2006, p. 104; resaltado propio).

No obstante, creo que este optimismo soslaya algunos inconvenientes adicionales que no parecen poderse pasar por alto tan fácilmente. $\mathrm{Y}$ esto sería así incluso si la tesis de la identidad entre proposiciones normativas y enunciados de deber jurídico fuera correcta. Dejando al margen los problemas de carácter ontológico, ${ }^{33}$ son determinantes en este punto aquellos de carácter dogmático: los concernientes a la determinación de las condiciones bajo las cuales puede considerarse que las normas jurídicas existen en relación con un determinado ordenamiento. ${ }^{34}$

En este orden de ideas, las clásicas concepciones hilética y expresiva, como tentativas de respuesta a las cuestiones ontológicas, resultan de por sí insuficientes para determinar que ciertas normas existen como pertenecientes a un cierto sistema normativo. En el caso de la primera concepción, hacen falta criterios empíricos para la reducción del universo de normas, en el sentido de su existencia más básico, a las jurídicamente existentes. ${ }^{35}$ En el segundo, es necesario identificar y discriminar ciertos actos de habla específicos como expresivos de normas y, de modo primordial, de normas jurídicas. Para ambas cosas son necesarios criterios normativos específicos, cuya entidad ha de ser elucidada de todas maneras.

En efecto, resulta crucial contar con criterios que, cualquiera que sea la ontología que se asuma, delimiten las normas pertenecientes a un sistema jurídico de aquellas que no forman parte del mismo. Caracciolo ha sostenido que lo que se planteaba como una hipótesis ontológica es ahora un "interrogante conceptual", ${ }^{36}$ y Guastini lo ha planteado como una cuestión "de derecho positivo y, por lo tanto, dogmática" (Guastini 2013b, p. 146; traducción propia).

${ }^{33}$ Entiendo que dentro de este género de problemas han de incluirse, al menos, el consistente en la elucidación de qué tipo de entidades son las normas, si alguna, y el relativo a la determinación de las condiciones bajo las cuales puede decirse que ellas existen.

${ }^{34}$ Cfr. Guastini 2013b, p. 146, Guastini 2013a, p. 138.

${ }^{35}$ Véase Caracciolo 1997.

36 “En tal caso, el término 'derecho' puede funcionar como un nombre de ciertos conjuntos de normas identificados por la satisfacción de algún criterio empírico de pertenencia. De manera que son "normas positivas' las que integran esos conjuntos" (Caracciolo 1997, p. 175). 
En este contexto, saber si una norma pertenece al ordenamiento jurídico supone identificar y usar los criterios que el propio ordenamiento establezca como determinativos de la pertenencia de normas a él. De modo que, asumiendo por el momento hipotéticamente la tesis de la identidad entre proposición normativa y enunciado jurídico, y sin concederla, no cualquier asunción conceptual será igualmente satisfactoria para los fines de determinar qué se debe hacer jurídicamente. Habrá que identificar los criterios normativos, tratados y usados como tales por quienes identifican y usan esas normas para justificar y criticar acciones. ${ }^{37}$

Como resulta bastante evidente, Bulygin parece pensar que el paso de (la identificación de) las fuentes del derecho a la determinación de qué normas existen en el ordenamiento es más bien sencilla, tal como Duarte d'Almeida sugiere: para esto sería suficiente asumir o adoptar "nuestros métodos interpretativos ordinarios". En este orden de ideas, la tesis depende de la presuposición de la verdad del cognitivismo interpretativo como una tesis descriptiva de la práctica jurídica. Pero esto último es difícilmente aceptable.

Se trata de una postura que descarta con demasiada rapidez el problema, subrayado con insistencia por el escepticismo interpretativo, según el cual en la práctica efectiva el paso "de la disposición a la norma", para evocar a Guastini, no sólo no es sencillo sino que no es siquiera un proceso cognitivo. Esto es así, dado que las primeras son recalcitrantemente equívocas en virtud, precisamente, de que siempre son aplicables métodos interpretativos conducentes a resultados distintos, esto es, criterios de pertenencia vigentes de modo contemporáneo que conducen a diversas interpretaciones como producto. ${ }^{38}$ Más o menos radicalmente, más o menos moderadamente, autores en esta línea subrayan el hecho innegable de que los jueces llegan a distintos resultados alegando siempre estar aplicando el derecho, y sin reconocer que están creando derecho nuevo.

En consecuencia, dado que "nuestros métodos interpretativos" ofrecen siempre distintas posibilidades potencialmente "correctas" de resolución acerca de qué normas existen, ni una ni otra norma pueden considerarse obviamente pertenecientes al sistema normativo de referencia, o bien todas ellas han de considerarse tales. Mas si esto último es así, tanto elegir una u otra de esas normas como perteneciente al

${ }^{37}$ Véase Caracciolo 2013, p. 34.

${ }^{38}$ Véanse Bayón Mohino 2002, p. 63; Arena 2012, p. 310; Chiassoni 1998; Chiassoni 2002; Tarello 1980, en especial el cap. VIII, pero también § 51, y Guastini 2011, cap. III, § 3 . 
ordenamiento, así como aplicarla a un caso, no puede considerarse el deber del juez, al menos no sin contar con algún criterio normativo ulterior, i.e., sin asumir una concepción interpretativa en términos normativos. ${ }^{39}$

En una revisión del concepto de proposición normativa orientada según esas observaciones, Guastini ha dicho incluso que sólo allí donde una de las interpretaciones posibles prevalezca en la doctrina y (especialmente) en la jurisprudencia,

[c]uando, y sólo cuando, una de las dos interpretaciones alternativas se torne interpretación dominante - cuando una de las dos normas, y no la otra, sea generalmente aplicada por los jueces - se podrá decir que esa norma, y no la otra, pertenece al sistema jurídico (existe en él). (Guastini 2013b, p. 152; traducción propia.)

Esto parece indicar que cualquiera que sea el "compromiso conceptual" que se asuma desde el punto de vista teórico, resulta como mínimo insuficiente para los fines de determinar cuándo una norma existe para un participante, pero resulta sobre todo insuficiente para decir qué es lo que jurídicamente se debe hacer desde ese punto de vista. En efecto, a más de que los officials mismos pueden discrepar acerca de cuáles son y cuáles deben ser los criterios de identificación admisibles, lo cierto es que los jueces dicen haber aplicado el derecho incluso en los casos en que los escépticos (moderados) consideran que lo han creado (i.e., fuera del "marco" de interpretaciones "admisibles"). Los "compromisos conceptuales" asumidos o quizás, siendo más realista, las posturas dogmáticas así adoptadas, tienen consecuencias normativamente cruciales. Ellas determinan, en última instancia, qué es lo que jurídicamente debe hacerse (como mínimo, qué es lo que debe hacer el juez si quiere aplicar el derecho). ${ }^{40}$ Sólo

${ }^{39}$ Ésta es, por ejemplo, la estrategia deliberada de Laporta 2007.

${ }^{40}$ Guastini ha llegado a manifestar sus dudas al respecto: "No sé decir si el uso de un criterio de identificación debe ser calificado como actitud 'interna' o 'externa' (aunque me inclinaría a decir: externa), pero lo que es cierto es que un uso tal no presupone elección moral o política" (Guastini 2004, § 4 (iii); traducción propia). Comparto plenamente lo segundo, aunque tendería a decir que la actitud es interna. Quizás se trate "meramente" del uso de reglas conceptuales: "[p]ero ello requiere contar con el concepto, y contar con el concepto significa contar con él desde el interior" (Shiner 1992, p. 149; traducción propia). En un sentido mucho más abarcador, éste es el punto de Winch 2008 [1958]. Podrá decirse que se trata de normas distintas dado que la "conceptual" no es una regla justificativa de conductas; pero esto sigue siendo discutible en todo caso, ya que es (la elección de) esa regla conceptual la que determina en última instancia qué es lo que según el derecho se 
sobre la base de asunciones tales podría sostenerse la conclusión de que,

[e]s posible, en principio, identificar el conjunto de todas las proposiciones normativas verdaderas referentes al sistema jurídico dado, lo cual implica que es posible establecer cuáles son las obligaciones y los permisos establecidos por el derecho. Es especialmente importante determinar cuáles son los deberes del juez en un caso dado. (Bulygin 2006, p. 104)

Desde esta óptica, la idea de asumir o adoptar los métodos interpretativos a fin de decir (¿o decidir?) cuáles son las normas que forman parte de un ordenamiento normativo parece todo lo que tiene que ocurrir para que tenga sentido afirmar que se está hablando desde un punto de vista: el jurídico. Después de todo, soslayar el problema dependía de asumir o adoptar nuestros "métodos interpretativos ordinarios". Y si ellos arrojan diversos resultados potenciales, dependerá además de contar con criterios para decidir cuál de esos métodos ha de elegirse y utilizarse en cada caso o clase de casos.

Sea como fuere, vale la pena recordar, remitiendo al parágrafo precedente que aun cuando hubiera criterios para determinar cuál es la interpretación unívocamente correcta de una fuente, esto sería todavía un indicador insuficiente de que se debe actuar jurídicamente como esa norma indica. Una vez más: salvar la distancia que hay entre disposición normativa y norma jurídica no significa de por sí superar también el espacio que hay entre la determinación de pertenencia de esa norma al ordenamiento y la determinación de si lo que ella dispone debe ser llevado a cabo. Esto último depende, además, no de la asunción (moral o cualquier otra) de que la norma debe ser obedecida, sino del juicio de validez interno, con todo lo que ello implica: ¿puede un juicio tal llevarse a cabo sin asumir postura normativa alguna?

debe hacer. Ésta es una discusión que excede los límites de este trabajo. Pueden verse al respecto: Bulygin 1991c [1976], Guastini 1996, Ruiz Manero 1990, pp. 138-139, Muffato 2007. Recientemente, Cristina Redondo ha propuesto entender la distinción entre punto de vista interno y punto de vista externo en dos sentidos divergentes. En un primer sentido, la distinción apunta a la comprensión o no del concepto. En este primer sentido, sin duda, el teórico habría de ubicarse en el punto de vista interno, adoptando la regla conceptual. En el segundo, en cambio, la distinción apunta a la adopción o no de un compromiso normativo, en términos de reconocerles a las normas identificadas, a partir de la adopción de la regla conceptual, el carácter de razones para la acción. En este segundo sentido, el teórico ha de ubicarse en un punto de vista externo (Redondo 2017). 


\section{Conclusiones}

En este trabajo se ha intentado evaluar qué queda de la intuición de Raz según la cual, para proferir enunciados de deber jurídico informativos, es necesario adoptar un punto de vista específico. Como punto de partida se han asumido como correctas las críticas que desechan el problema a partir del rechazo de las premisas metaéticas razianas. De tal modo, se ha concedido que la adopción de un punto de vista en términos de fuerza vinculante - hipotética o no- carece de importancia. Se ha argumentado, sin embargo, que esas críticas desechan como "no problemático" más de lo admisiblemente descartable. Se mostró que quedan aún cuestiones irresueltas que dan fuerza a esa intuición, aunque con un matiz diferente. En primer lugar, se ha insistido en que identificar los enunciados de deber jurídico, o sus condiciones de verdad, con proposiciones normativas, o sus condiciones de verdad, no está justificado. De manera que aun cuando pudiere informarse acerca de la existencia de normas jurídicas, todavía quedaría un espacio por salvar al ir de la proposición normativa al enunciado de deber jurídico. En segundo lugar, se ha enfatizado el hecho de que incluso si se identificasen enunciados tales con proposiciones normativas, resultaría todavía un presupuesto indispensable individuar criterios jurídicos determinativos de la pertenencia de ciertas normas al sistema, y adoptarlos para tales fines. Se ha traído a colación, en este sentido, la circunstancia de que los criterios utilizados en la práctica son sumamente variados y que no arrojan resultados unívocos. Así que aun cuando pudiera informarse acerca de la existencia de una fuente de derecho e incluso de las opciones interpretativas con que se cuenta, todavía quedaría un espacio por salvar para ir de la fuente en cuestión a la norma existente. Ambas aristas problemáticas dejan espacio para pensar que a fin de determinar lo jurídicamente debido, resulta inevitable asumir el punto de vista jurídico. Si a partir de allí es factible o no emitir enunciados en términos genuinamente informativos, neutrales, es algo que todavía ha de ser discutido. ${ }^{41}$

${ }^{41}$ Algunas de las ideas aquí vertidas fueron discutidas en el Tequila Seminar celebrado en la Ciudad de México, a cuyos integrantes agradezco. Posteriormente expuse algunos puntos en el XXII Seminario Luso-Hispano-Franco-Italiano de Teoría del Derecho. Doy las gracias especialmente por sus lecturas y sugerencias también a Jorge Cerdio, Riccardo Guastini, Nicola Muffato, Alberto Puppo, Pablo Rapetti y Cristina Redondo. Asimismo agradezco a dos dictaminadores anónimos por sus útiles sugerencias y comentarios. 


\section{BIBLIOGRAFÍA}

Alchourrón, Carlos E., 1991, “Condicionalidad y la representación de las normas jurídicas”, en Alchourrón y Bulygin 1991, pp. 267-280.

Alchourrón, Carlos E. y Eugenio Bulygin, 1991, Análisis lógico y derecho, Centro de Estudios Constitucionales, Madrid.

Arena, Federico José, 2012, "Desacuerdos ambiguos, convenciones equívocas", en P. Luque Sánchez y G.B. Ratti, Acordes y desacuerdos: Cómo y por qué los juristas discrepan, Marcial Pons, Madrid, pp. 277-314.

Austin, J.L., 1975, How to Do Things with Words, Harvard University Press, Cambridge, Mass.

Bayón Mohino, Juan Carlos, 2002, “Derecho, convencionalismo y controversia", en Navarro y Redondo 2002, pp. 57-92.

——, 2000, "Deber jurídico", en E. Garzón Valdés y F.J. Laporta (comps.), El derecho y la justicia, Trotta, Madrid, pp. 313-329.

Bayón Mohino, Juan Carlos, 1991, La normatividad del derecho: deber jurídico y razones para la acción, Centro de Estudios Constitucionales, Madrid.

Brink, David O., 1986, "Externalist Moral Realism”, Southern Journal of Philosophy, vol. 24, no. Sl, pp. 23-4l.

Bulygin, Eugenio, 2007, Il positivismo giuridico, trad. y ed. P. Chiassoni, R. Guastini y G.B. Ratti, Giuffrè, Milán.

—— 2006, El positivismo jurídico, Fontamara, México.

- 2003, "El papel de la verdad en el discurso normativo", Doxa: Cuadernos de Filosofía del Derecho, vol. 26, pp. 79-85.

_- 1991a [1982], "Normas, proposiciones normativas y enunciados jurídicos", en Alchourrón y Bulygin 1991, pp. 169-193.

—_, 1991b [1981], "Enunciados jurídicos y positivismo: respuesta a Raz", en Alchourrón y Bulygin 1991, pp. 427-438.

—_, 1991c [1976], "Sobre la regla de reconocimiento", en Alchourrón y Bulygin 1991, pp. 383-391.

Caracciolo, Ricardo, 2013, "Proposiciones normativas y objetividad: revisión de un problema", Análisis filosófico, vol. 33, pp. 31-46.

—_, 1997, "Existencia de normas", Isonomía, vol. 7, pp. 159-178

Chiassoni, Pierluigi, 2002, "Los juegos interpretativos. La interpretación de la ley desde un enfoque griceano", en Navarro y Redondo 2002, pp. 185208.

—_ 1998, "L'ineluttabile scetticismo della "scuola genovese" ", Analisi e diritto, pp. 21-76.

Duarte d'Almeida, Luís, 2011, "Legal Statements and Normative Language", Law and Philosophy, vol. 30, no. 2, pp. 167-199.

Finnis, John, 2011, Natural Law and Natural Rights, Oxford University Press, Oxford.

Garzón Valdés, Ernesto, 1993, “Algo más acerca de la relación entre derecho y moral", Derecho, ética y política, Centro de Estudios Constitucionales, Madrid, pp. 317-335. 
Guastini, Riccardo, 2013a, Distinguendo ancora, Marcial Pons, Madrid.

— 2013 b, "Due concezioni delle norme", en Guastini 2013a, pp. 137143.

—— 2013c, "Esistenza empirica di norme", en Guastini 2013a, pp. 145152.

, 2013d, "Proposizioni normative", en Guastini 2013a, pp. 153-164.

2011, Interpretare e argomentare, Giuffrè, Milán.

, 2004, "Il positivismo come filosofia dei 'giuristi positivi'?", Politeia, vol. 73 , pp. 104-110.

— , 2000, "Sollsätze: An Exercise in Hard Legal Positivism", Rechtstheorie, vol. 31, no. 2, pp. 185-196.

—_, 1996, "Conoscenza senza acettazione", Distinguendo: studi di teoria e metateoria del diritto, Giappichelli, Turín, pp. 321-341.

Hart, H.L.A., 2012a, "Postcript", en Hart 2012b, pp. 238-276.

—. 2012b [1961], The Concept of Law, Oxford University Press, Oxford.

Clarendon Press/Oxford University Press, Oxford/Nueva York, pp. 118.

—_, 1982, "Legal Duty and Obligation", Essays on Bentham: Studies in Jurisprudence and Political Theory, Clarendon, Oxford, pp. 127-161. —_, 1966, "Il concetto di obbligo", Rivista di filosofia, vol. 57, no. 2, pp. 125-140.

Kelsen, Hans, 2009 [1960], Teoría pura del derecho, trad. Roberto Vernengo, Porrúa, México.

——, 1985 [1979], Teoria generale delle norme, Einaudi, Turín.

Laporta, Francisco J., 2007, El imperio de la ley: una visión actual, Trotta, Madrid.

MacCormick, Neil, 1994 [1978], Legal Reasoning and Legal Theory, Clarendon Press, Oxford.

MacCormick, Neil y Zenon Bankowski, 1986, "Speech Acts, Legal Institutions, and Real Laws", en N. MacCormick y P. Birks (comps.), The Legal Mind: Essays for Tony Honoré, Clarendon Press, Oxford, pp. 121-133.

Muffato, Nicola, 2013, "Tertium non datur: sulla pretesa autonomia concettuale degli asserti distaccati", Analisi e Diritto, pp. 275-311.

—. 2009, "Resta qualcosa da dire sulla polivocità degli enunciati deontici?", Diritto e Questioni Pubbliche, vol. 9, pp. 589-623.

—_, 2007, "Asserti interni: prescrizioni o asserzioni?", Analisi e Diritto, pp. $12-37$.

Navarro, Pablo E., 2016, "Enunciados jurídicos, proposiciones normativas y necesidad práctica", Analisi e Diritto, 2016, pp. 101-126.

—_ 2012a, "Positivismo jurídico, proposiciones y enunciados normativos", Revista Brasileira de Filosofia, vol. 238, no. 1, pp. 11-29.

- 2012b, “Son los enunciados jurídicos proposiciones normativas?”, Doxa: Cuadernos de Filosofía del Derecho, vol. 35, pp. 629-639. 
Navarro, P.E. y M.C. Redondo (comps.), 2002, La relevancia del derecho: Ensayos de filosofía jurídica, moral y política, Gedisa, Barcelona.

Nino, Carlos Santiago, 1994, Derecho, moral y política: una revisión de la teoría general del derecho, Ariel, Barcelona.

- , 1993, "Breve nota sulla struttura del ragionamento giuridico", Ragion Pratica, vol. 1, pp. 34-37.

—_ 1985, La validez del derecho, Astrea, Buenos Aires.

Raz, Joseph, 2011, From Normativity to Responsibility, Oxford University Press, Oxford.

— 1999 [1975], Practical Reason and Norms, Oxford University Press, Oxford.

- 1998, "The Purity of the Pure Theory", en S.L.E. Paulson, Normativity and Norms: Critical Perspectives on Kelsenian Themes, Clarendon, Oxford, pp. 237-252.

- _ 1982, La autoridad del derecho: ensayos sobre derecho y moral, trad. Rolando Tamayo, Universidad Nacional Autónoma de México, México.

—_, 1980, "Postcript", The Concept of a Legal System: An Introduction to the Theory of Legal System, Clarendon Press, Oxford, pp. 209-238.

- 1979a, The Authority of Law: Essays on Law and Morality, Clarendon Press, Oxford.

- 1979b, "Kelsen's Theory of the Basic Norm", en Raz 1979a, pp. $122-145$.

$\ldots$ 77.

—_, 1979d, "Legal Validity”, en Raz 1979a, pp. 146-159.

Redondo, María Cristina, 2017, "La ambigüedad interno/externo. Una reflexión sobre los conceptos y los enunciados jurídicos", ponencia presentada en el coloquio SADAF 2017: "El futuro de la filosofía práctica", Buenos Aires, 10-11 de agosto de 2017.

—— 1996, La noción de razón para la acción en el análisis jurídico, Centro de Estudios Constitucionales, Madrid.

Ross, Alf, 2014 [1961], "El concepto de validez y el conflicto entre el positivismo jurídico y el derecho natural", El concepto de validez y otros ensayos, trad. Genaro Carrió et al., Fontamara, México, pp. 7-29.

Ruiz Manero, Juan, 1990, Jurisdicción y normas: dos estudios sobre función jurisdiccional y teoría del derecho, Centro de Estudios Constitucionales, Madrid.

Scarpelli, Uberto, 1967, “Le 'proposizioni giuridiche' come precetti reiterati”, Rivista Internazionale di Filosofia del Diritto, vol. 44, no. 3, pp. 465-482.

Searle, John R., 2001 [1969], Actos de habla: Ensayo de filosofía del lenguaje, Cátedra, Madrid.

Shiner, Roger A., 1992, Norm and Nature: The Movements of Legal Thought, Clarendon Press, Oxford. 
Tarello, Giovanni, 1980, L'Interpretazione della legge, Giuffré, Milán.

Toh, Kevin, 2007, "Raz on Detachment, Acceptance and Describability", Oxford Journal of Legal Studies, vol. 27, no. 3, pp. 403-427.

Von Wright, George Henrik, 1963, Norm and Action. A Logical Enquiry, Routledge and Kegan, Londres.

Williams, Bernard, 1979, "Internal and External Reasons", en R. Harrison, Rational Action, Cambridge University Press, Cambridge, pp. 101-113.

Winch, Peter, 2008 [1958], The Idea of a Social Science and its Relation to Philosophy, Routledge, Londres.

Recibido el 29 de marzo de 2017; aceptado el 8 de agosto de 2017. 